\title{
Mónica Tousaint (edit.), Diplomacia en tiempos de guerra. Memorias del embajador Gustavo Iruegas. Ciudad de México, Instituto Mora/CIALC-UNAM-La Jornada, 2013
}

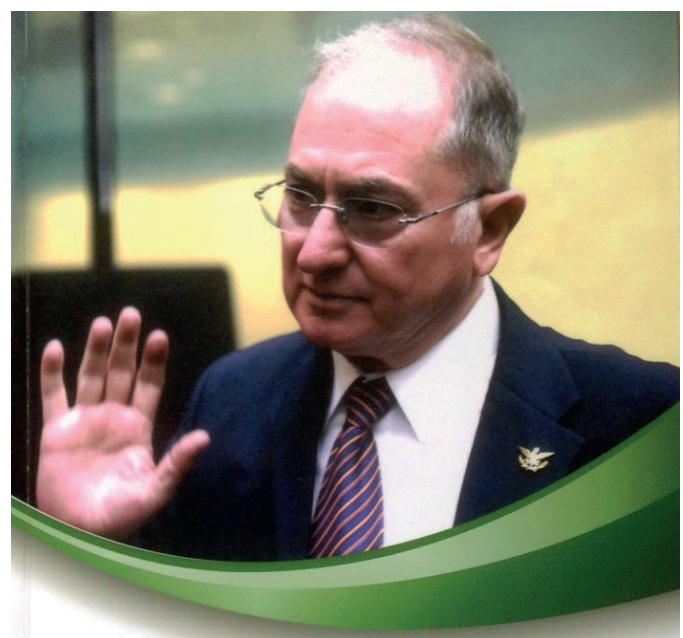

DIPLOMACIA EN TIEMPOS DE GUERRA

Memorias del embajador Gustavo Iruegas Mónica Toussaint

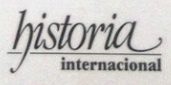

Cuando se habla del cuerpo diplomático en cualquier país, pero especialmente en los latinoamericanos, se piensa en una vida llena de comodidades, de muchas actividades sociales, de abundantes banquetes. Para los diplomáticos latinoamericanos, el servicio exterior ha sido un premio, un favor o un castigo. También ha servido para que algunos escritores en ciernes o que han demostrado un prometedor talento, favorecidos por el poder, adquieran experiencias del mundo y desarrollen sus cualidades y habilidades intelectuales, para que se dediquen a su arte. Es famosa la anécdota de cómo Pablo Neruda llegó a parar con un cargo diplomático en Rangún, tras jugar a ciegas con un globo terráqueo. Se sabe también que Octavio Paz, otro afamado premio Nobel de Literatura (1990), ingresó al Servicio Exterior Mexicano para complementar los fondos provenientes de la beca que le había sido otorgada por la Fundación Guggenheim, insuficientes para mantener a su recién creada familia. También se han dado casos en los que el designado no la ha pasado del todo bien al frente de una representación diplomática. Un ejemplo ilustrativo de estos es el de Rubén Darío. Son proverbiales las penurias económicas que constantemente experimentó quien ahora se nombra en Nicaragua como "nuestra máxima gloria nacional". El más destacado exponente del Modernismo hasta tuvo que pedir prestado el traje formal que vistió el día que presentó sus cartas credenciales ante Alfonso XIII, rey de España, porque no tenía fondos para comprarse o alquilar uno.

Pero hay otros casos que también son realmente excepcionales, aunque por otras razones: la de aquellos que tomando muy seriamente sus responsabilidades van más allá de los protocolos y las normas que rigen el actuar de los representantes diplomáticos en los países donde han sido designados. Uno de estos es el caso del embajador Gustavo Iruegas (1942-2008), quien debió hacerse cargo de la represen-

1 Doctor en Estudios Latinoamericanos. Docente del Colegio de Estudios Latinoamericanos de la Facultad de Filosofía y Letras, de la Universidad Nacional Autónoma de México. 
tación diplomática de la República Mexicana en Nicaragua en 1978, tras el retiro del embajador y meses antes de la ruptura de relaciones entre ambos países en mayo de 1979. También estuvo al frente de la sede mexicana en El Salvador, en 1980-1981, un período de serias convulsiones políticas y sociales que desembocaron en cruentos enfrentamientos bélicos.

La historiadora Mónica Toussaint, especialista en Centroamérica, entrevistó a Iruegas durante varias sesiones que sumaron numerosas horas de grabaciones, en las que recogió la trayectoria vital del diplomático y las peripecias que experimentó durante los más de treinta años que perteneció al Servicio Exterior Mexicano, hasta llegar a ocupar el cargo de subsecretario para América Latina y el Caribe de la Secretaría (Ministerio) de Relaciones Exteriores de México en el 2000, y que presenta en este volumen.

La vida del embajador fue la de un hombre perteneciente a una familia del interior mexicano, de recursos más bien modestos, que llegó a la capital donde realizó estudios de periodismo e historia en dos de las instituciones académicas más prestigiosas de su país, la Universidad Nacional Autónoma de México y El Colegio de México, aunque sin concluir las carreras elegidas, pero que le dieron las suficientes herramientas para comenzar a trabajar en Prensa y Publicidad, de la Secretaría de Relaciones Exteriores.

Sus memorias juveniles hablan de un México que ya no existe, donde los jóvenes de su generación confiaban en un futuro estable y disfrutaban con confianza de las posibilidades que ofrecía el Estado Mexicano en la etapa final o de agotamiento del nacionalismo revolucionario, dos décadas antes de que los devotos del neoliberalismo dieran un giro al país cuyas consecuencias experimentan ahora millones de mexicanos. De manera que el libro, si bien es autobiográfico, puede leerse también como un retrato a grandes pinceladas de ese proceso que se profundizará en el 2000, año en que por primera vez en su historia el Partido Revolucionario Institucional (PRI) perdió las elecciones generales frente a un adversario político: el Partido Acción Nacional, y tuvo que abandonar Los Pinos y entregar las riendas del gobierno. En un comentario analítico, Iruegas lo resume así: "Cuando Vicente Fox llegó a la presidencia, en realidad no era un cambio a la derecha. México ya estaba a la derecha desde antes, eso habría que tenerlo claro".

Pero lo que más interesa o debe interesar a los lectores centroamericanos, y por lo por lo cual recomiendo la lectura de este texto, son los novedosos como valiosos detalles que cuenta Iruegas desde su papel de diplomático - en verdad muy atípico- de esos años de luchas y esperanzas revolucionarias en los que México actuó como ese "hermano mayor" latinoamericano, como era idealizado en América Central. Son detalles que completan partes importantes de ese rompecabezas que es la historia de esa época, como cuando narra hechos desconocidos y muy ilustrativos sobre el apoyo de su país a los movimientos guerrilleros centroamericanos. Pero también interesa por las confidencias que hace de algunos interiores de la diplomacia mexicana y de su convivencia personal como diplomático latinoamericano en diversos países del continente y al otro lado del Atlántico. 
El libro responde muchas interrogantes que seguramente se ha hecho no sólo el investigador acucioso sobre este fascinante momento histórico, sino también cualquier otro ciudadano que vivió con mucha expectación esos acontecimientos: ¿Qué hizo que un funcionario diplomático pusiera en riesgo no sólo su cargo y las comodidades que éste representa, sino también hasta su propia vida? ¿Cómo vivieron los funcionarios mexicanos que daban asilo y albergaban a revolucionarios sandinistas fugitivos, en peligro de muerte por la persecución que de ellos hacía la guardia somocista en los últimos meses de la dictadura? ¿Cómo se vivía en la sede de la Embajada Mexicana, saturada de perseguidos políticos? ¿Cómo se pudo atender y alimentar a tantos asilados? ¿Cuál fue el intríngulis que se vivió en los pasillos y oficinas de la sede central de la diplomacia mexicana, mientras se discutía y se decidía la postura a tomar 126 frente al creciente conflicto centroamericano? ¿Cuál es la visión del embajador Iruegas acerca del giro que dio en su política exterior el gobierno mexicano bajo la presidencia de Vicente Fox? ¿Cómo se dio la invasión y la posterior desocupación de los invasores, por la policía cubana, de la sede de la Embajada de México en La Habana en 2002? ¿Qué se habló entretelones antes, durante y después del penoso incidente del gobierno de Vicente Fox con el comandante Fidel Castro, y por qué se dio ese hecho, calificado por Iruegas como el episodio más lamentable que México ha tenido en materia diplomática? ¿Cómo expresa su sentir y demanda que se haga su voluntad el gobierno estadounidense a los funcionarios de los países latinoamericanos, a quienes consideran sus subordinados? ¿Cuál fue la lógica que estaba tras el giro que dio México, de distanciarse de la comunidad latinoamericana y sumarse a la cola del águila estadounidense?
No corresponde contestarlas en esta breve reseña, pero de la primera puede adelantarse que el apoyo brindado desde la sede diplomática de México en Managua tuvo dos fundamentos esenciales. Por un lado, la formación y las simpatías hacia las causas progresistas y hasta revolucionarias latinoamericanas adquirida por un estudiante de ciencias políticas en la UNAM en la década de los míticos años sesenta del siglo XX, de enormes convulsiones sociales y políticas en el mundo; un período en donde, en palabras del embajador, la mayor parte de los profesores y de estudiantes eran francamente de izquierda. Por otro, la luz verde, o mejor, las instrucciones que recibió Iruegas de su superior en la Secretaría de Relaciones Exteriores, para que hiciera todo lo que estuviera a su alcance en favor de "esa gente y su revolución", en referencia a los revolucionarios sandinistas que luchaban por derrocar al dictador Anastasio Somoza.

El texto es generoso además en anécdotas graciosas, duras, muy puntillosas, así como en juicios sobre reconocidos personajes de distintos países y, por supuesto, de la política mexicana. No pocas de estas opiniones son realmente severas, y bien podrían calificarse como juicios históricos. Por ejemplo, refiriéndose al primer canciller del gobierno de Fox, el reconocido intelectual Jorge Castañeda, Iruegas cuenta:

"Cuando Jorge [Castañeda] ya venía muy encaminado a ser canciller, Andrés Rozental nos dijo: 'Por la amistad que les tengo, les quiero decir lo siguiente. Jorge va a ser muy mal canciller'. Una vez que se dio el anuncio oficial de la designación, Jorge hizo una fiesta en su casa a la que asistió su hermana Marina. Alguien medio cursilón sugirió que todo mundo hablara, que todos dijeran algo. 
Cuando le tocó a la hermana de Jorge, ella le dijo 'Lo que te puedo decir es que mis padres estarían muy contentos, pero no entenderían nada de todo esto'. Tiempo después recordé los comentarios de Andrés y Marina cuando comprobé dos cosas: primero, que Jorge no sabía el oficio y, segundo, que era un tipo voluntarioso".

Posteriormente agrega: "El día primero de diciembre, entre los invitados estaba Fidel Castro. Jorge le tenía pánico, era una cosa de risa. (...) Algunos se morían de la risa porque Jorge decía: 'Gustavo, Gustavo, viene Fidel, están poniendo carteles en las calles'. Tenía miedo de que hiciera una gran concentración pública en el Zócalo, eso le daba pánico”. Y más adelante: “(...) Jorge tenía esa doble actitud de un miedo cerval a Fidel y unas ganas de hacerle daño a la revolución, como revancha”.

Como colofón, el texto también recoge el testimonio de Susie Iruegas, la esposa del diplomático mexicano, quien si bien nunca apareció en primera plana de los diarios durante las diversas peripecias vivida por el embajador, como históricamente ha ocurrido y ocurre con todas las mujeres, fue igualmente protagonista de estas historias y no sólo como apoyo o respaldo a su marido. Una prueba de esto fue cuando sirvió como "correo" para entregar una altísima suma de dinero para apoyar la causa sandinista. Anécdotas que, además de generar un inmenso disfrute al leerlas, son ilustrativas para comprender las formas, "el mundo real" e interno de la diplomacia mexicana.
En definitiva es un libro lleno de fascinantes recuerdos que además de leerse con deleite, nos informan de aquello que normalmente no se recoge en las notas periodísticas ni en los libros de historia. No obstante, al leerlo también debemos tener presente que toda memoria, que todo recuerdo contiene implícito uno o muchos olvidos; olvidos de acciones, palabras y escenas que no se recuerdan consciente o inconscientemente, o bien porque no se fue testigo presencial de ellas. Y en este sentido, las acciones del embajador narradas en este volumen tienen un correlato, se inscriben también en un contexto mucho más amplio. Pues mientras Iruegas y su esposa Susie apoyaban a los sandinistas que buscaban refugio en la sede diplomática mexicana, en esos mismos años en la capital de México y otras ciudades mexicanas miles de estudiantes, trabajadores y no pocos intelectuales, también se empeñaban en demandar al gobierno mexicano que tomara medidas más fuertes frente a la crisis revolucionaria que vivía el país centroamericano. Estos esfuerzos se realizaban desde tres Coordinadoras de Solidaridad con el Pueblo de Nicaragua, que se organizaron con ese propósito. Una de las medidas que esos sectores demandaban de su gobierno fue la ruptura de relaciones diplomáticas con el régimen somocista, de la cual uno de los artífices, cuando finalmente ocurrió, fue precisamente Iruegas, hecho que también recoge el libro. Por eso puede afirmarse que la labor desarrollada por el embajador Iruegas durante su estadía en Nicaragua y El Salvador fue la expresión de la solidaridad de un hombre, de un gobierno y de un pueblo. 